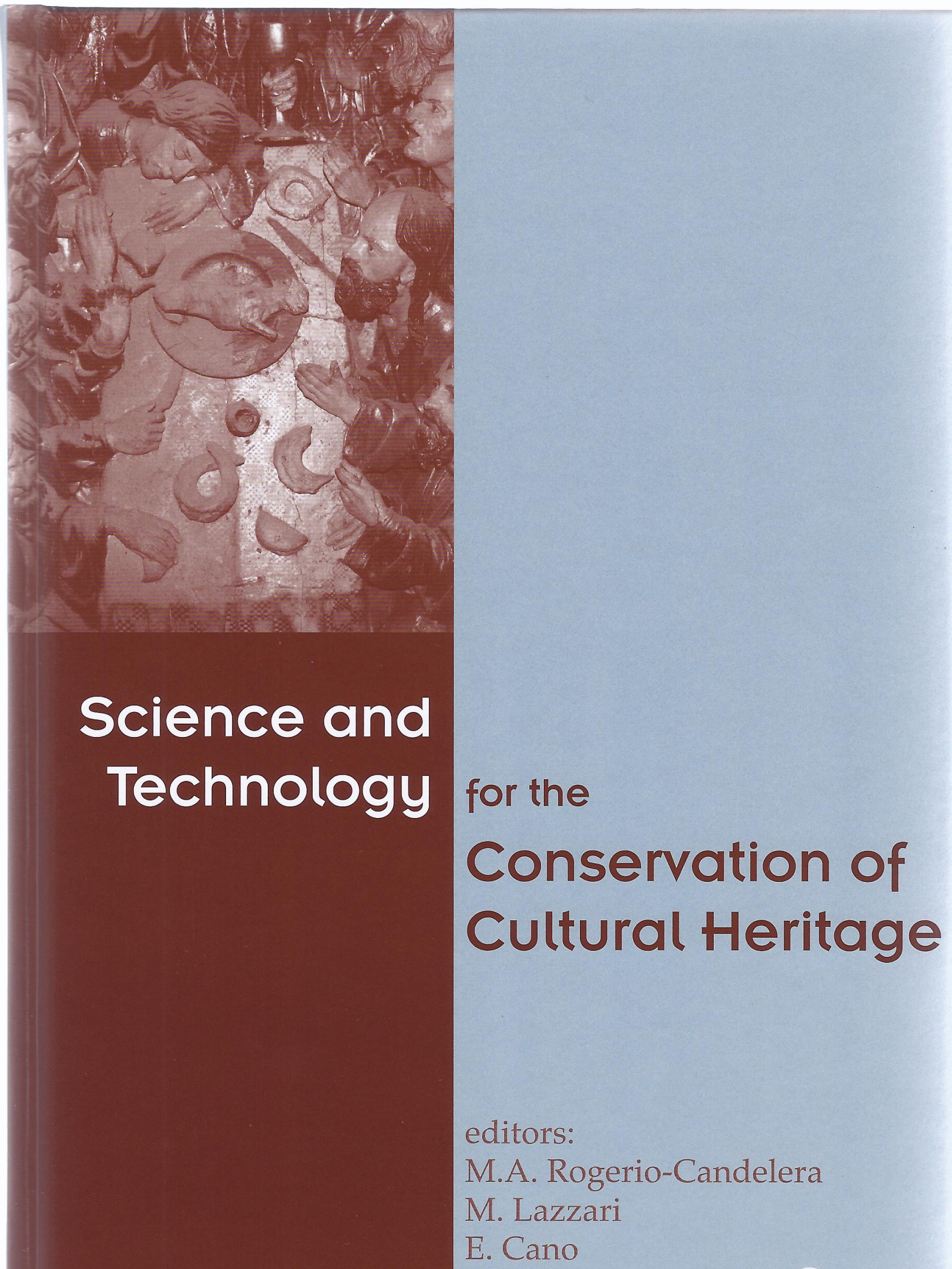




\title{
Old materials, new solutions
}

\author{
A. Macarrón, A. Calvo \& R. Gil \\ Faculty of Fine Arts, Complutense University, Madrid, Spain
}

\begin{abstract}
The contribution of this paper in the Conference is to present the first results collected at the first phase of the documental study R \& D \& I project "Materiales y métodos en los tratamientos de refuerzo de pintura sobre lienzo mediante entelados a la gacha: documentación, función y conservación", supported by the Ministerio de Economía y Competitividad (MINECO). One of the aims of the project is the compilation and evaluation of the recipes, methodologies and tendencies developed during centuries through documental and experimental studies, to prove their behaviour physical-chemical and stability, in addition to propose improvements and preventive conservation guidelines.
\end{abstract}

\section{INTRODUCTION}

In this Conference, we present the first results of the documental study conducted in the 1st phase of the $\mathrm{R}+\mathrm{D}+\mathrm{i}$ project "Materials and methods of pasta linings for the reinforcement of canvas paintings: documentation, functionality and conservation", supported by the Ministerio de Ciencia e Innovación (MICINN) and led by the Complutense University of Madrid (UCM). A multidisciplinary team of international experts in this area has been meeting representing the countries where pasta linings have been usually carried out, as the Mediterranean basin (Spain, Portugal, France and Italy) and northern Europe (Denmark, Netherlands and the UK).

Ana Macarrón (IP) (UCM) and Ana Calvo, UCM and Research Center for Science and Technology in art (CITAR), Laura Fuster and Sofía Vicente, Polytechnic University of Valencia (UPV), Paul Ackroyd (National Gallery, London), Marion F. Mecklenburg (Smithsonian Institution), Joan Reyfsneyder, (The Florence Conservation Resource Center), Mikkel Scharff and Cecil Krarup, (Royal Danish Academy of Fine Arts, School of Conservation), Matteo Rossi (Laboratorio Torrimprieta), Aurealia Chevalier (Université Paris I Panthéon Sorbone, Atélier Chevalier), Kate Seymour (Stichting Restauratie Atelier Limburg, SRAL), Erminio Signorini (Cesmar 7).

The Museo Thyssen-Bornemisza, Museo Nacional del Prado and Patrimonio Nacional, from Spain, also collaborate in the project. As Promoters Contributors (EPO) takes part the companies CTS and Productos de Conservación. The research is integrated into the activities of "Research Group UCM (930420): Documentation Techniques, Heritage Conservation and Restoration", Facultad de Bellas Artes, UCM. One of the aims of the project is to compare and evaluate the various recipes, methodologies and tendencies developed over centuries, beginning with the documental study conducted during the first phase of the research.

It is tried to study from an experimental point of view, their physicochemical behavior, and its stability against environmental factors (RH, T, light), mechanical traction, and its compatibility related to the materials of the artwork paintings, taking into account the technical characteristics of the works of art, the mutations of the materials, and the environmental conditions of each country. The Smithsonian Institution (USA) also participates in the project advising on the structural tests to be performed.

Trying to determine the possible effectiveness and current convenience of a reinforcement treatment that has evolved over more than 300 years in Europe, whose materials are very 


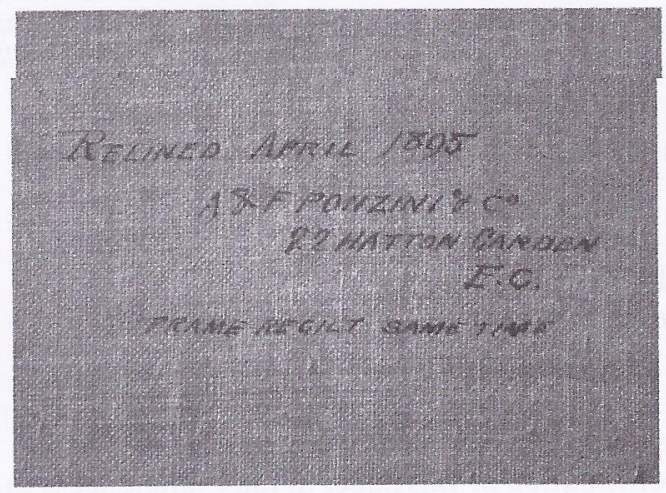

Figure 1. Signature of a lining intervention. (Photo: José Mendes. CITAR-Universidade Catotina Portuguesa, Porto).

homogeneous and compatible with most canvas paintings, barely toxic, cheap and sustainable comparing them with the existing synthetic adhesives that has certain advantages, bu also some drawbacks, and to suggest improvements and preventive conservation guidelines.

\section{METHODOLOGY AND FIRST RESULTS OF THE PROJECT}

\subsection{Phase 1: Documental study}

The structure of the project goes in three phases: documental, experimental and informatie In the first phase of the research collection of old and new recipe has been made, from tie consultation of archives, treaties, invoices of materials, reports of restoration and inform tion/data provided by restores through two inquiries developed for the old and current: lining research. These inquiries, translated into English and French, have been sent directi to official institutions and private restorers from Spain and Europe and published on the website of the Spanish Group of the International Institute of Conservation (GE-IIC).

The purpose of these questions is to establish a unified approach for issues concernin: linings performed with this procedure previously and nowadays, in which wondered dreent aspects such as the terminology used to describe the procedure, details of the painting institutions, restorers and dates of intervention. Additionally, materials and proportions a the recipes, tools and methodology used, observation of the lining results (formation an: correction of deformities, reversibility, stability, etc.) current conservation status of the paining (if the painting preserves the lining, or if it was necessary a later intervention due to the etc.), environmental conditions of the exhibition and storage; and documentary sources firat which the information has been extracted.

\subsection{Selection of case studies}

Amongst the documented artworks, a selection of paintings treated with this procedure has be examined in order to verify its current conservation status. It should be mentioned the followin: cases studies: the equestrian portraits of Felipe III and Margarita de Austria by Velázquez. III fiesta del vino" by Brueghel, and "El sueño del Patricio" by Murillo, all of them in the Prati Museum; and "Cristo crucificado" by José Ribera, in the Diputación Foral de Álava.

\subsection{Development of database}

Moreover a relational Access Database has been designed to manage all the collected, allows consulting and searching from different approaches and compar. 


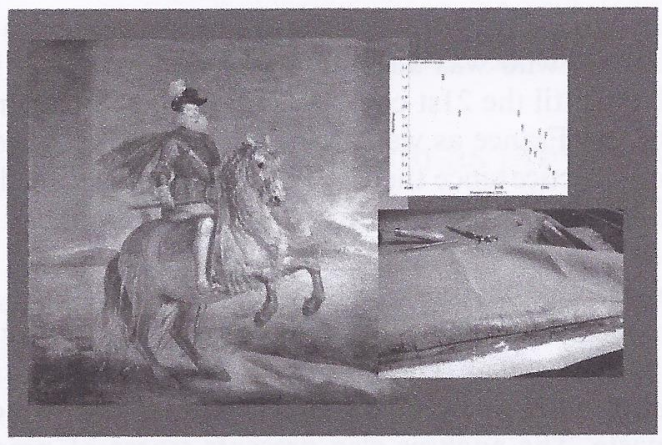

Figure 2. Case study: "Felipe III a caballo" by Velázquez. Museo del Prado. Restored by Andrés de la Calleja in the eighteenth century. FTIR spectrum of a sample lining adhesive. Removing the additions, process of reinforcement and protection of edges.

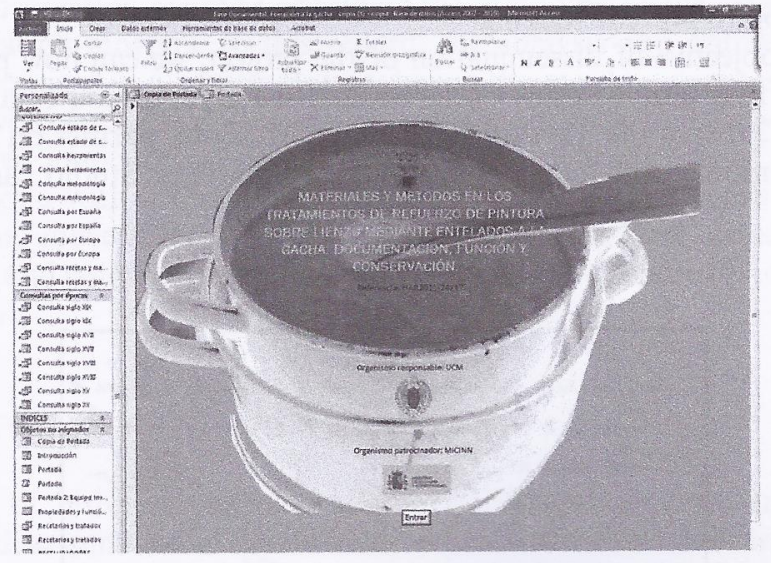

Figure 3. Screenshot of Database Access on lining.

ous recipes and procedures. The information of interventions can be consulted by periods, regions, materials, restorers, recipes books, treaties, among other bibliographies.

\subsection{Phase 2: Experimental study}

At this phase a study of adhesive qualities, dimensional and mechanical behavior will be performed (tensing and peeling tests), before and after the accelerate aging cycles on the testers that had been prepared with selected recipes and techniques to evaluate their stability, safety and innocuous properties and mechanical behavior.

Besides it will be done the chemical analysis of the samples that can be extracted from the original art work, in order to carry out the identification of the main components and different additives which have in their composition.

At this moment the only information that we have is about the adhesive from some of the selected works of art.

\section{PROVISIONAL RESULTS}

The results achieved are:

- Historical documentation of the procedure, by compiling recipes and processes used, throughout history until the present time. 
- Valuable information about unknown cases and recipes have been collected, as those di Juan García de Miranda, who was an initiator of the procedure in the 17th century in Spain and many others until the 21st century, from recipe books and reports in Portugel. Denmark, UK, Italy and France as well as the signatures of the restorer on the back af some works, common practice since the late eighteenth and early nineteenth centuries

- Creation of a library of images of the works of art studied and of the analysis performed.

- Elaboration of an interactive database.

- Analysis has been made on the adhesive of three paintings from the Prado Museum by Velázquez, Murillo and Brueghel. The first two are oils on linen canvas, and the third is glue-tempera. On all three, it was found starch + animal glue, which are the main ingsdients of the glue paste. The analysis also presents traces of pine resin, corresponding perhaps to Venice turpentine present in most recipes, and traces of grease (information provided for this project by $\mathrm{M}^{\mathrm{a}}$ Dolores Gayo, Head of the Analysis Laboratory at Pradi: Museum). "Grease", perhaps linseed and nut oil, appears in some lining material orders it 18 th and 19 th century. There are references to the oleaginous cover that was given to the painting and iron to prevent sticking.

- Regarding the objective of dissemination of the project, we can now point out the presentation of the first results in this Congress, and the organization of a One-day Seminar (October 15th, 2012) in the Thyssen-Bornemisza Museum, partner on the project on IIIings titled "Reinforcement treatments of canvas paintings: Studio cases, evolution ant behavior".

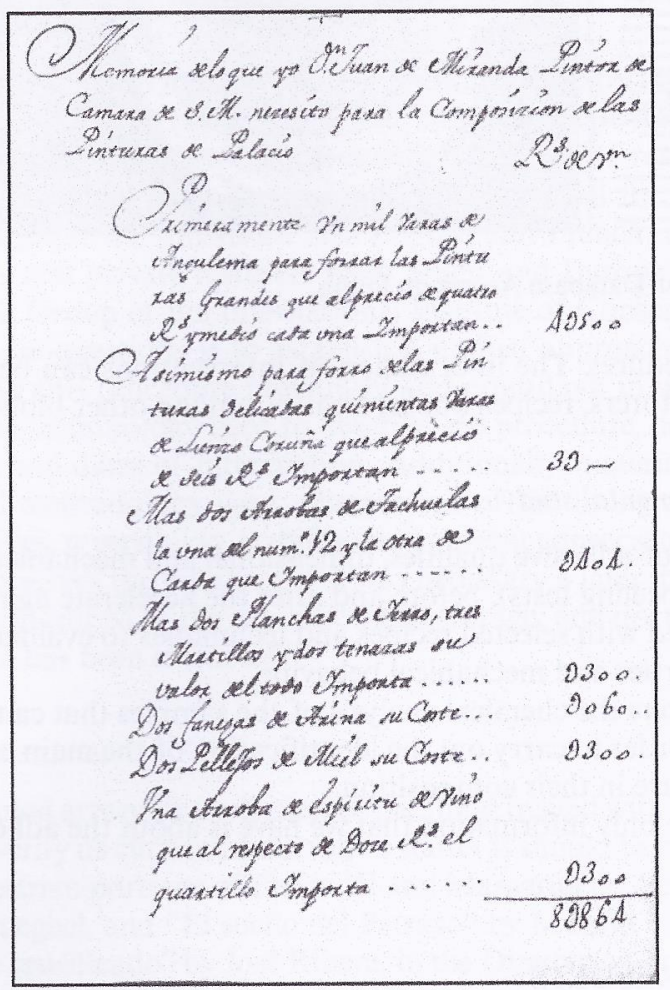

Figure 4. Invoice of lining material by Juan de Miranda, in 1735. (Archivo de Palacio Real. P. Nacional). 
From $2^{\text {nd }}$ to $5^{\text {th }}$ October 2012 an International Congress on Science and Technology for the conservation of Cultural Heritage was held in Santiago de Compostela, Spain, organized by the Universidade of Santiago de Compostela on behalf of TechnoHeritage Network. The congress was attended by some 160 participants from 10 countries, which presented a total of 145 contributions among plenary lectures, oral, and poster communications. The congress was dedicated to eight topics, namely (1) Environmental assessment and monitoring (pollution, climate change, natural events, etc.) of Cultural Heritage; (2) Agents and mechanisms of deterioration of Cultural Heritage (physical, chemical, biological), including deterioration of modern materials used in Contemporary Art and information storage; (3) Development of new instruments, non invasive technologies and innovative solutions for analysis, protection and conservation of Cultural Heritage; (4) New products and materials for conservation and maintenance of Cultural Heritage; (5) Preservation of industrial and rural heritage from the 19 th and 20th centuries; (6) Security technologies, Remote sensing and Geographical Information Systems for protection and management of Cultural Heritage; (7) Significance and social value of Cultural Heritage; and (8) Policies for conservation of Cultural Heritage. This volume publishes a total of ninety three contributions which reflect some of the most recent responses to the challenge of cultural assets conservation. 